\title{
ABSORBAN ION LOGAM CU (II) BERBASIS HIDROGEL SUPERABSORBAN CMC-G- PKA/NAALG DENGAN TEKNIK IRADIASI SINAR GAMMA
}

\author{
Permono Adi Putro ${ }^{1}$, Ahmad Sofyan Sulaeman ${ }^{1, \text { b) }}$, Erizal ${ }^{2}$, Imas Ratna \\ Ermawati $^{1}$ \\ ${ }^{1}$ Program Studi Pendidikan Fisika, Fakultas Keguruan dan Ilmu Pendidikan, UHAMKA, Jakarta, Indonesia. \\ ${ }^{2}$ Pusat Aplikasi Isotop dan Radiasi (PAIR) - Badan Tenaga Nuklir Nasional (BATAN), Kawasan Nuklir Ps. \\ Jumat, Jakarta, Indonesia
}

Email: b) ahmadsofyansulaeman@gmail.com

\begin{abstract}
Abstrak
Hidrogel Superabsorban (HSA) CMC-g-PKA/NaAlg telah disintesis menggunakan iradiasi sinar gamma sebagai crosslinker dengan dosis $10 \mathrm{kGy}$. HSA disintesis dengan variasi massa CMC, yaitu 1,0 g, 1,5 g, 2,0 g, dan 2,5 g. Kemampuan HSA dalam menyerap ion logam $\mathrm{Cu}$ (II) telah dipelajari menggunakan spektrofotometer UV-Vis. Pengujian dilakukan dengan variasi konsentrasi ion logam $\mathrm{Cu}$ (II) yaitu, $1 \%$, $2 \%, 3 \%, 4 \%$, dan $5 \%$ selama 30 menit. Nilai absorbansi pada ion logam $\mathrm{Cu}$ (II) meningkat seiring dengan peningkatan massa CMC. Nilai absorbansi terbesar, yaitu $74 \%$ pada massa CMC 2,5 g. Pengujian FTIR mencirikan adanya interaksi antara gugus $(\mathrm{OH})$ hidroksil, $\left(\mathrm{NH}_{2}\right)$ amina, dan karboksilat $(\mathrm{COOH})$, terhadap ion logam $\mathrm{Cu}$ (II) pada bilangan gelombang 3653,18 1/cm, 1442,75 1/cm, dan $1587,421 / \mathrm{cm}$.
\end{abstract}

Kata-kata kunci: HSA, Absorbansi, ion logam Cu (II), UV-Vis, FTIR

\begin{abstract}
Hydrogel Superabsorbent (HSA) CMC-g-PKA/NaAlg has been synthesized using gamma-ray irradiation as a $10 \mathrm{kGy}$ crosslinker. HSA is synthesized with CMC mass variations, i.e. $1.0 \mathrm{~g}, 1.5 \mathrm{~g}, 2.0$ g, 2.5 g. HSA's ability to absorb $\mathrm{Cu}$ (II) metal ions has been studied using the UV-Vis spectrophotometer. The test was performed with variation of $\mathrm{Cu}$ (II) ion concentration i.e. $1 \%, 2 \%, 3 \%$, $4 \%$, and $5 \%$ for 30 minutes. The absorbance value of $\mathrm{Cu}$ (II) metal ions increases with increasing mass of CMC. The largest absorbance value, i.e., $74 \%$ in CMC mass $2.5 \mathrm{~g}$. The FTIR test characterizes the interaction of hydroxyl $(\mathrm{OH})$, amine (NH2), and Carboxylic $(\mathrm{COOH})$, groups to $\mathrm{Cu}$-(II) metal ions in wave number $3653,181 / \mathrm{cm}, 1442,751 / \mathrm{cm}$, and $1587,421 / \mathrm{cm}$.
\end{abstract}

Keywords: HSA, Absorbance, Cu (II) metal ions, UV-Vis, FTIR. 


\section{PENDAHULUAN}

Salah satu polutan yang mendapat banyak perhatian adalah polutan logam-logam yang dihasilkan dari alam dan aktivitas manusia seperti, aktivitas industri dalam skala besar ataupun kecil seiring berkembanganya penggunaan bahan industri yang menghasilkan limbah cair mengandung residu organik dan anorganik [1]. Keberadaannya dilingkungan merupakan masalah yang perlu mendapat perhatian serius, karena dapat memberikan efek toksik yang berbahaya bagi kehidupan manusia, binatang dan tumbuhan seperti, kematian atau mengalami perubahan lingkungan pada konsentrasi tinggi bahkan pada konsentrasi rendah sekalipun [2-4].

Logam berat yang berbahaya bagi lingkungan khususnya dilingkungan perairan salah satunya yaitu ion logam $\mathrm{Cu}$ (II). Ion Logam $\mathrm{Cu}$ (II) dapat memasuki lingkungan melalui jalur alamiah dan non alamiah. Pada jalur alamiah, logam mengalami siklus perputaran dari kerak bumi, ke dalam air, mengendap dan akhirnya kembali ke dalam kerak bumi [5], misalnya melalui peristiwa erosi atau pengikisan batuan mineral dan persenyawaan $\mathrm{Cu}$ (II) di atmosfer yang turun melalui hujan [4]. Ion logam $\mathrm{Cu}$ (II) tidak dapat dihancurkan oleh mikroorganisme dan dapat terakumulasi dalam tubuh manusia [6]. Dalam dosis tinggi dapat menyebabkan gejala Glycemic Index (GI), ginjal, hati, muntaber, anemia, koma, dan kematian. Keberadaannya dilingkungan dapat menimbulkan rasa kesat, warna, korosi pada baja [7], sambungan dan peralatan dapur [8] serta dilingukungan perairan, akan menyebabkan ikan mengalami penyakit, kelainan syaraf, cacat, dan lain-lain [9]. Hingga saat ini upaya untuk menanggulangi polutan logam $\mathrm{Cu}$ (II) umumnya dapat dilakukan dengan proses absorpsi, pertukaran ion, pemisahan dengan membran, dan pengendapan menggunakan material organik maupun anorganik berbasis absorban seperti, lignin [10], Cobalt ferrite [11], HSA [12], Tricalcium phospate [6], dan lain-lain.

Absorban ion logam $\mathrm{Cu}$ (II) berbasis HSA lebih diunggulkan, karena memiliki beberapa sifat seperti cepat menyerap cairan, kapasitas penyerapan tinggi, tidak beracun, fleksibel, berkekuatan mekanis yang baik, dan tahan terhadap bahan kimia agresif dan suhu tinggi [13]. Selain itu, pengembangan superabsorban multi-komponen yang berasal dari polimer alam dan aditif ramah lingkungan memunculkan minat yang besar karena menguntungkan dalam segi komersial dan lingkungan serta sangat dihargai sebagai material yang berpotensi untuk menghijaukan dunia pada abad 21 [14]. Hidrogel dapat disintesis menggunakan beberapa bahan baku seperti, asam akrilat (AAc) [15], Carboxymethyl cellulose (CMC) [16], Sodium Alginat (NaAlg) [17].

AAc dapat digunakan untuk sintesis HSA karena merupakan monomer hidrofilik yang dalam

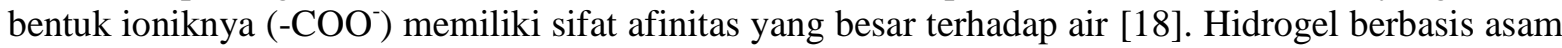
akrilat menunjukkan sifat khusus dengan adanya asam karboksilat sebagai gugus samping anion dalam jaringannya. keberadaan gugus anion dalam asam akrilat dapat dilakukan dengan netralisasi gugus asam dalam fase cair (biasanya dengan natrium atau larutan kalium hidroksida), dan diikuti dengan pengikatan silang untuk polimerisasi [19].

Poli (kalium akrilat) merupakan polimer polielektrolit yang dapat membentuk ion ketika berada dilingkungan berair yang menyebabkan terjadinya pembengkakan dengan volume yang cukup besar, karena adanya ikatan hidrogen atau pembentukan ikatan kovalen. Selain menyerap air, PKA dapat menyerap ion logam $\mathrm{Cu}$ (II) [20] yang dipengaruhi oleh pelepasan ion kalium dari hasil kopolimerisasi antara $\mathrm{KOH}$ dan asam akrilat [21]. Sifat yang dimiliki PKA sangat menguntungkan untuk sintesis HSA, sebab PKA tidak beracun dan sangat sensitif terhadap perubahan suhu dan $\mathrm{pH}$. Studi baru tentang HSA berbasis PKA menunjukkan karakteristik mekanik dan fisik yang baik seperti elongasi, regangan, ketahanan tegang [22].

CMC merupakan turunan selulosa yang dapat mereka dapat memberikan karakter biodegradable ketika dicampur dengan bahan lain dan tingginya kekakuan yang dapat meningkatkan sifat fisik HSA [23]. HSA berbasis CMC memiliki kesetimbangan serapan dan tingkat pembengkakan yang tinggi di dalam air dan larutan garam. Selain itu, HSA ini merupakan pilihan tepat untuk menyerap ion logam $\mathrm{Cu}$ (II) karena dapat berikatan dengan gugus karboksil yang terkandung dalam CMC [12,24].

$\mathrm{NaAlg}$ dikenal sebagai senyawa turunan polisakarida yang terdiri dari sejumlah besar gugus hidroksil bebas $(\mathrm{OH})$ dan karboksil $(\mathrm{COOH})$ polimer linier yang dapat membentuk gel dalam kondisi tertentu. Bahan ini memiliki kemampuan menstabilkan sifat, viskositas tinggi dalam larutan berair, 
hidrofilik dan biokompatibel serta unggul dari segi ekonomis $[14,25,26]$. Sifat fisiko-kimia dari $\mathrm{NaAlg}$ hampir didominasi oleh kelompok $\left(\mathrm{OH}_{\text {dan }} \mathrm{COO}^{-}\right)$[14] di mana kandungan tersebut dapat bereaksi dengan ion logam $\mathrm{Cu}$ (II).

Berdasarkan beberapa informasi yang telah diperoleh, HSA CMC-g-PKA-NaAlg yang disintesis menggunakan iradaisi sinar gamma memiliki kelebihan dalam meningkatkan proses gelasi, lebih mudah dibuat, memiliki kekuatan mekanik yang baik [16], dan mampu menyerap ion logam $\mathrm{Cu}$ (II) dalam jumlah besar untuk mempertahankan ion logam $\mathrm{Cu}$ (II) yang terserap dengan cara mengubah larutan ion logam $\mathrm{Cu}$ (II) menjadi endapan [8].

\section{METODE PENELITIAN}

Proses absorpsi ion logam $\mathrm{Cu}$ (II) dilakukan dengan cara melarutkan serbuk HSA CMC-g$\mathrm{PKA} / \mathrm{NaAlg}$ ke dalam larutan ion logam $\mathrm{Cu}$ (II). kemudian sisa larutan dianalisis menggunakan UVVis untuk mengetahui perubahan nilai absorbansi setelah diberi perlakuan menggunakan HSA. Sebelum dilarutkan dalam larutan ion logam Cu (II) HSA dikarakterisasi FTIR untuk mengetahui gugus fungsi yang memiliki peran dalam proses absorpsi ion logam $\mathrm{Cu}$ (II). Data yang diperoleh dari absorban ion logam $\mathrm{Cu}$ (II) dan analisis FTIR dalam bentuk notepad di plot menggunakan software gnuplot 4.6.

HSA CMC-g-PKA-NaAlg yang disintesis menggunakan iradiasi sinar gamma, aquadest, Tembaga (II) sulfat hidrat $\left(\mathrm{CuSO}_{4} .5 \mathrm{H}_{2} \mathrm{O}\right)$ (merck), Spektrofotometer UV-Vis Genesis 2, Amerika, Fourier Transform Infra Red (FTIR Shimadzu Prestige-21), Japan sebagai bahan dan alat yang digunakan dalam penelitian ini.

Pembuatan larutan ion logam dilakukan dengan variasi konsentrasi $1 \%, 2 \%, 3 \%, 4 \%$, dan $5 \%$ dalam $100 \mathrm{~mL}$ aquadest, selanjutnya diuji menggunakan spektrofotometer UV-Vis. Kemudian sebanyak 0.1 g HSA dilarutkan ke dalam larutan ion logam $\mathrm{Cu}$ (II), masing-masing HSA dengan massa CMC berbeda ( $1 \mathrm{~g}, 1.5 \mathrm{~g}, 2.0 \mathrm{~g}$, dan $2.5 \mathrm{~g}$ ) dilarutkan pada larutan ion logam $\mathrm{Cu}$ (II) dengan konsentrasi yang berbeda pula. Selanjutnya HSA yang telah dilarutkan diaduk menggunakan Magnetic stirrer selama 30 menit. Setelah itu, HSA disaring dan larutan yang tersisa diukur kembali menggunakan spektrofotometer UV-Vis. Pengukuran kemampuan absorpsi HSA terhadap ion logam $\mathrm{Cu}$ (II) memenuhi persamaan (1) dan (2) sebagai berikut [18]:

$$
X(\%)=\frac{A_{t}}{A_{0}} \times 100
$$

$$
\text { Ion yang Terserap }=(100-X) \%
$$

Di mana $X$ adalah ion logam $\mathrm{Cu}$ (II) yang tersisa dalam larutan, $A_{t}$ adalah nilai absorbansi dari larutan ion logam setelah absorpsi, dan $A_{t}$ nilai absorbansi larutan ion logam awal (sebelum absorpsi). Sebagai pendukung dalam analisa serapan ion logam $\mathrm{Cu}$ (II), FTIR digunakan untuk mengetahui gugus fungsi yang terdapat dalam HSA dengan rentang panjang gelombang $4000 \mathrm{~cm}^{-1}-400 \mathrm{~cm}^{-1}$. 


\section{HASIL DAN PEMBAHASAN}

Berdasarkan hasil pengujian menggunakan spektrofotometer UV-Vis, kemampuan HSA dalam mengabsorpsi ion logam $\mathrm{Cu}$ (II)ditunjukkan pada GAMBAR 1 .

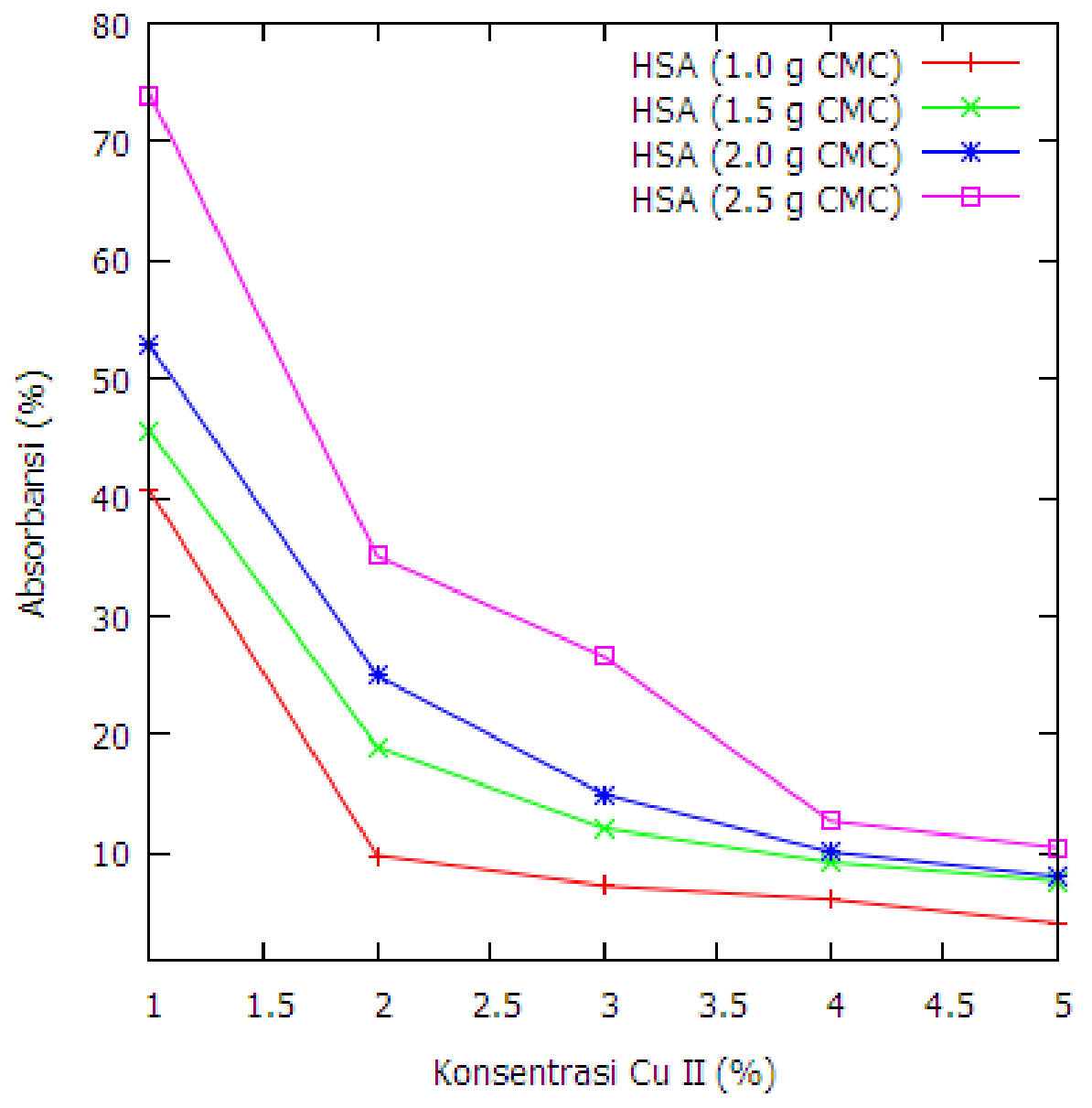

GAMBAR 1. Kurva serapan ion logam Cu (II)

Peningkatan serapan ion logam $\mathrm{Cu}$ (II) yang signifikan seiring meningkatnya massa CMC dalam HSA yang dapat dilihat pada GAMBAR 1. Konsentrasi CMC yang lebih tinggi memberikan kekuatan yang penting untuk mengatasi semua resistensi transfer massa polutan antara fase air dan padat, sehingga meningkatkan penyerapan ion logam $\mathrm{Cu}$ (II). Pengurangan kandungan Ion logam $\mathrm{Cu}$ (II) dilakukan dengan cara diserap kemudian diendapkan oleh HSA [9]. Serapan logam tertinggi terdapat pada HSA dengan berat CMC $2.5 \mathrm{~g}$ yakni $74 \%$ dari $1 \%$ ion logam $\mathrm{Cu}$ (II) yang terkandung dalam larutan. Hal ini menunjukkan kapasitas serapan disekitar HSA yang tersedia lebih besar dari konsentrasi ion logam $\mathrm{Cu}$ (II) sebelum kesetimbangan absorpsi-desorpsi tercapai [12]. Dengan demikian, konsentrasi ion logam $\mathrm{Cu}$ (II) yang lebih tinggi mengakibatkan kemampuan serapan HSA menurun. Selain itu, serapan ion pada HSA dipengaruhi oleh pelepasan ion kalium dari hasil kopolimerisasi antara $\mathrm{KOH}$ dan asam akrilat, peningkatan persentase kelompok karboksil yang dinetralkan oleh $\mathrm{KOH}$ akan meningkatkan penyerapan ion logam $\mathrm{Cu}$ (II) dan serapan air menurun [21]. hal ini relevan dengan hasil percobaan yang menggunakan $\mathrm{NaOH}$ untuk kopolimerisasi asam akrilat [21]. Secara fisik perubahan warna pada larutan ion logam $\mathrm{Cu}$ (II) setelah HSA dilarutkan terlihat pada GAMBAR 2. 


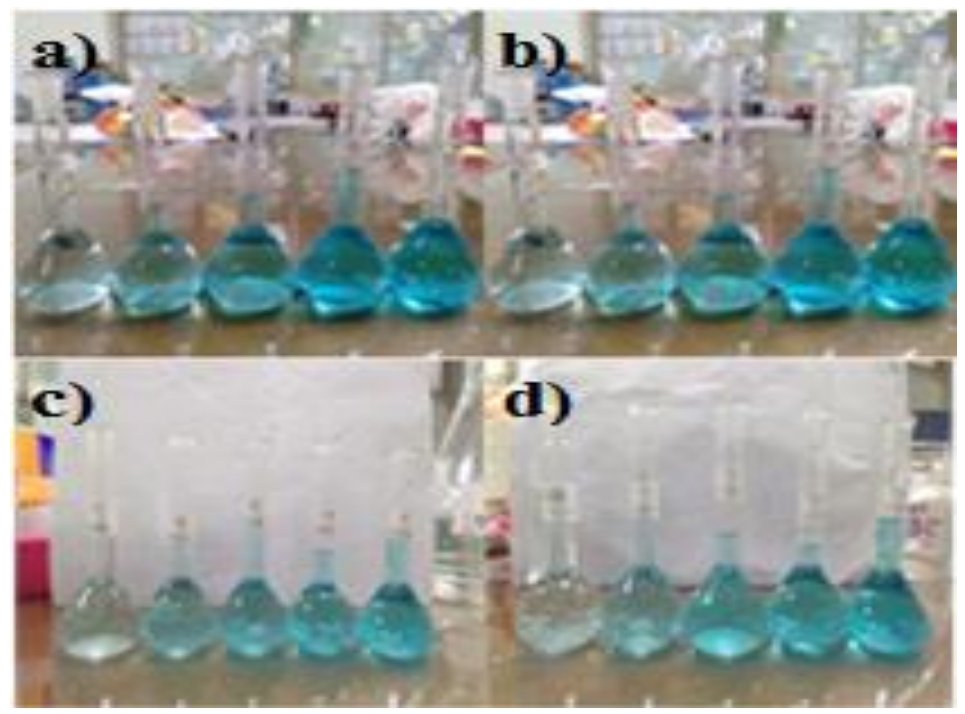

GAMBAR 2. Perubahan fisik larutan ion logam Cu (II) setelah HSA $1.0 \mathrm{~g}$ (a); $1.5 \mathrm{~g}$ (b); $2.0 \mathrm{~g}$ (c); $2.5 \mathrm{~g}$ (d) dilarutkan.

Secara kimia, peristiwa ini disebabkan oleh adanya jaringan matriks yang mengandungn gugus karboksilat $(-\mathrm{COOH})$, amina $\left(-\mathrm{ONH}_{2}\right)$ yang dapat bereaksi dengan ion logam $\mathrm{Cu}(\mathrm{II})$ [18], karena ion logam $\mathrm{Cu}$ (II) memiliki daya tarik kuat untuk mengikat elektron bebas dalam oksigen dari kelompok karboksil [27]. Selain dengan gugus karboksil dan amida, ion logam $\mathrm{Cu}$ (II) juga dapat bereaksi dengan gugus hidroksil $(\mathrm{OH})$.

$$
\begin{gathered}
-\mathrm{NH}_{2}+\mathrm{Cu}^{2+} \rightarrow-\mathrm{NH}_{2} \mathrm{Cu}^{2+} \\
-\mathrm{NH}_{2} \mathrm{OH}^{-}+\mathrm{Cu}^{2+}\left(\mathrm{orCuOH}^{+}\right) \leftrightarrow-\mathrm{NH}_{2} \mathrm{OH}^{-} \ldots \mathrm{Cu}^{2+}\left(\text { or- }-\mathrm{NH}_{2} \mathrm{OH}^{-} \ldots \mathrm{CuOH}^{+}\right) \\
\left(\mathrm{R}-\mathrm{COO}^{-}\right)+\mathrm{Cu}^{2+} \rightarrow\left(\mathrm{R}-\mathrm{COO}^{-}\right)-\mathrm{Cu}^{2+}
\end{gathered}
$$

Berdasarkan persamaan (3) - (5) menunjukkan mekanisme reaksi antara gugus-gugus fungsi yang terkandung dalam HSA dengan ion logam $\mathrm{Cu}$ (II). Di mana persamaan (3) merupakan reaksi amina dengan ion logam $\mathrm{Cu}(\mathrm{II})$, persamaan (4) merupakan reaksi amina dan hidroksil dengan ion logam $\mathrm{Cu}$ (II) [28], dan persamaan (5) merupakan reaksi gugus karbosilat dengan ion logam $\mathrm{Cu}$ (II) [29]. Hasil karakterisasi menggunakan FTIR mengindikasikan beberapa gugus fungsi yang dapat bereaksi dengan ion logam $\mathrm{Cu}$ (II) dalam HSA ditunjukkan pada GAMBAR 3. 


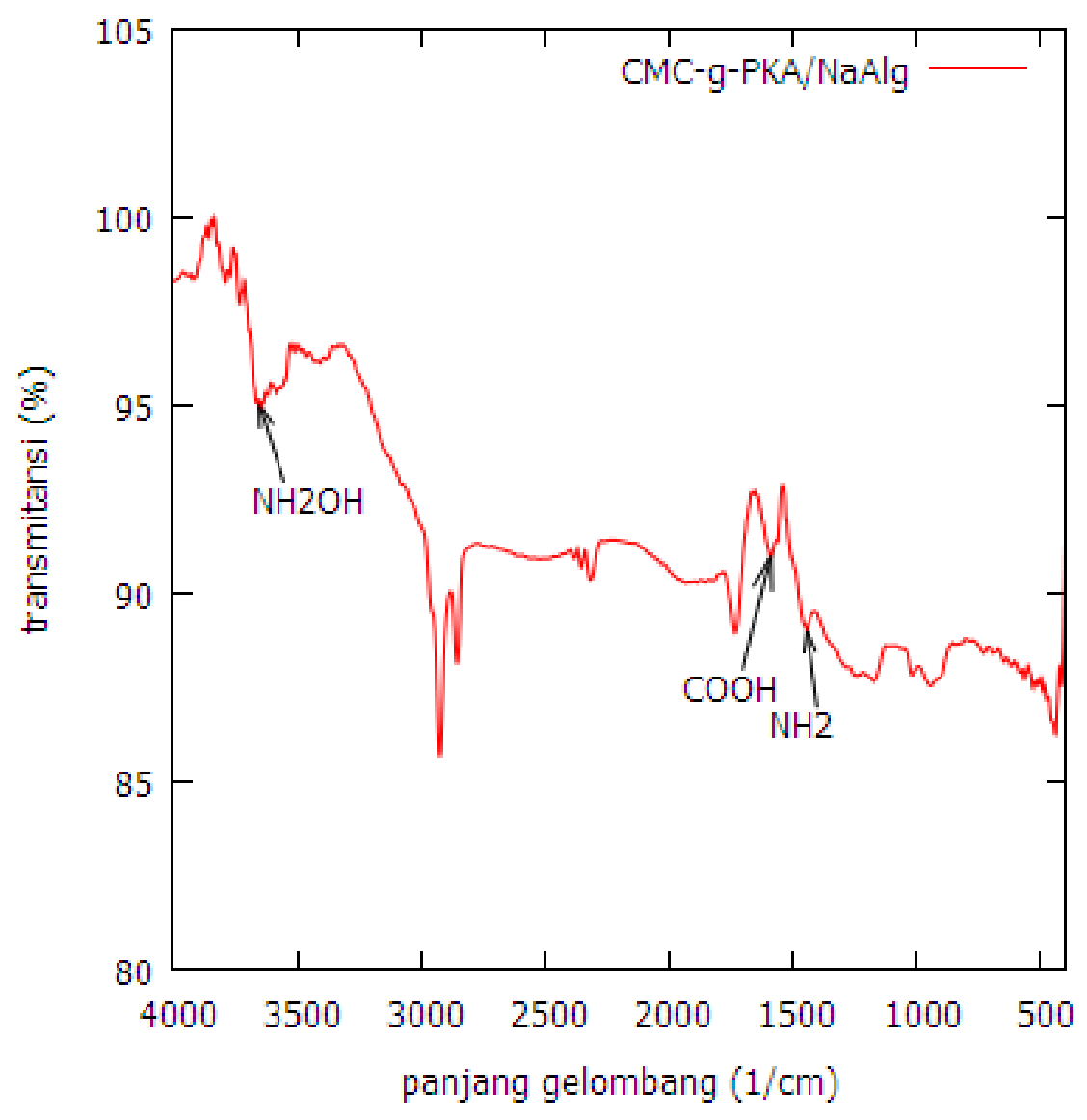

GAMBAR 3.Spektrum FTIR HSA

Reaksi gugus karboksilat $(-\mathrm{COOH})$ dengan ion logam $\mathrm{Cu}$ (II) ditunjukkan pada bilangan gelombang 1587,45 $\mathrm{cm}^{-1}$ [30] dan 1442,75, Puncak ini dikaitkan dengan $(\mathrm{C}=\mathrm{O})$ peregangan kelompok fungsional karboksamida [31]. Kemudian gugus hidroksil $(\mathrm{O}-\mathrm{H})$ dan amida $(\mathrm{N}-\mathrm{H})$, berdasarkan hasil karakterisasi FTIR, gugus tersebut ditunjukkan pada pita $3653,18 \mathrm{~cm}^{-1}$ sesuai dengan gugus $\mathrm{O}-\mathrm{H}$ overlapping dengan $\mathrm{N}-\mathrm{H}[32]$.

\section{SIMPULAN}

HSA CMC-g-PKA/NaAlg memiliki kemampuan menyerap ion logam $\mathrm{Cu}$ (II) dengan baik dan mengalami peningkatan dalam menyerap ion logam $\mathrm{Cu}$ (II) seiring bertambahnya berat CMC. Hal ini disebabkan oleh besarnya kapasitas serapan yang tersedia dan adanya jaringan matriks yang mengandung gugus fungsi seperti hidroksil, karboksilat, amina, dan karboksamida. HSA ini dapat direkomendasikan untuk digunakan sebagai absorban ion logam $\mathrm{Cu}$ (II).

\section{UCAPAN TERIMAKASIH}

Penulis mengucapkan terima kasih kepada Pusat Aplikasi Isotop dan Radiasi Badan Teknologi Nuklir Nasional (PAIR BATAN) atas fasilitas serta dukungannya terhadap penelitian yang telah dilaksanakan. 


\section{REFERENSI}

[1] D. A. Irawati, B. Hamzah, and N. Rahman, "Pengaruh ion logam $\mathrm{Cu}$ (II) terhadap persen ekstraksi ion $\mathrm{Pb}$ (II) menggunakan teknik emulsi membran cair," J. Akad. Kim., vol. 5, no. 4, pp. 172-177, 2016.

[2] P. Sathiyanarayanan and R. J. Karunakaran, "Batch adsorptive removal of copper (II) using carboxymethyl cellulose (CMC), polyethylene glycol (PEG) and montmorillonite (MMT) clay ternary blend," J. Chem. Pharm. Res., vol. 7, no. 4, pp. 1099-1108, 2015.

[3] A. Lesbani, S. Yusuf, and R. A. M. Melviana, "Karakterisasi kitin dan kitosan dari cangkang kepiting bakau (Scylla Serrata),” J. Penelit. Sains, vol. 14, no. 3 (C), pp. 32-36, 2011.

[4] W. A. Nugraha, "Kandungan logam berat pada air dan sedimen di perairan socah dan kwanyar kabupaten bangkalan," J. Kelaut., vol. 2, no. 2, pp. 158-164, 2009.

[5] A. Mu'nisa and Nurham, "Analisis cemaran logam berat tembaga $(\mathrm{Cu})$ pada ikan tembang (sardinella gibbosa) yang dipasarkan di makassar," Bionature, vol. 11, no. 2, pp. 61-64, 2010.

[6] S. Chotijah, A. Fadli, and Komalasari, "Kinetika adsorpsi ion logam $\mathrm{Cu}^{2+}$ menggunakan tricalcium phospate sebagai adsorben," Jom FTEKNIK, vol. 5, no. 1, pp. 1-5, 2018.

[7] H. P. Pradityo, "Analisis kegagalan pipa primary separator," Institut Pertanian Bogor, 2012.

[8] N. I. Said, "Metoda penghilangan logam merkuri di dalam air limbah industri," vol. 6, no. 1, pp. 136-148, 2010.

[9] N. Priyanto, Dwiyitno, and F. Ariyani, "Kandungan logam berat ( $\mathrm{Hg}, \mathrm{Pb}, \mathrm{Cd}$, dan $\mathrm{Cu})$ pada ikan, air , dan sedimen di waduk Cirata, Jawa Barat," J. Pascapanen dan Bioteknol. Kelaut. dan Perikan., vol. 3, no. 1, pp. 69-78, 2008.

[10] Lelifajri, “Adsorpsi ion logam Cu (II) menggunakan lignin dari limbah serbuk kayu gergaji," J. Rekayasa Kim. dan Lingkung., vol. 7, no. 3, pp. 126-129, 2010.

[11] F. A. Nurdila, N. S. Asri, and E. Suharyadi, "Adsorpsi logam tembaga (Cu), besi (Fe), dan nikel (Ni) dalam limbah cair buatan menggunakan nanopartikel cobalt ferrite $\left(\mathrm{CoFe}_{2} \mathrm{O}_{4}\right), " J$. Fis. Indones., vol. XIX, no. 55, pp. 23-27, 2015.

[12] R. K. Farag, S. M. El-Saeed, and M. E. Abdel-Raouf, "Synthesis and investigation of hydrogel nanoparticles based on natural polymer for removal of lead and copper (II) ions," Desalin. Water Treat., vol. 57, no. 34, pp. 0-11, 2015.

[13] A. Wesołowska, S. Bednarz, and D. Bogdał, "Study of copper ions adsorption by itaconicbased hydrogels," 2014.

[14] Erizal, F. Lukitowati, I. Oktaviani, D. R. Barleany, B. Abbas, and Sudirman, "Synthesis and characterization of superabsorbent sodium alginate-g-poly (potassium acrylate) hydrogels prepared by using gamma irradiation," J. Kim. dan Kemasan, vol. 39, no. 1, pp. 9-16, 2017.

[15] F. Askari, S. Nafisi, H. Omidian, and S. A. Hashemi, "Synthesis and characterization of acrylic-based superabsorbents,” J. Appl. Polym. Sci., vol. 50, no. 10, pp. 1851-1855, 1993.

[16] T. Fekete, J. Borsa, E. Takács, and L. Wojnárovits, "Synthesis of carboxymethylcellulose/starch superabsorbent hydrogels by gamma-irradiation," Chem. Cent. J., vol. 11, no. 1, pp. 1-10, 2017.

[17] T. Yoshimura, M. Matsunaga, and R. Fujioka, "Alginate-based superabsorbent hydrogels composed of carboxylic acid-amine interaction: Preparation and characterization," EPolymers, vol. 9, no. 1, pp. 1618-7229, 2009.

[18] Erizal, "Sintesis hidrogel superabsorben poli (akrilamida-ko-kalium akrilat) dengan teknik radiasi dan karakterisasinya," J. Ilmiahh Apl. Isot. dan Radiasi, vol. 6, no. 2, pp. 105-116, 
2010.

[19] Erizal, B. Abbas, S. G. Sukaryo, and D. R. Barleany, "Synthesis and characterization superabsorbent hydrogels of partially neutralized acrylic acid prepared using gamma irradiation; swelling and thermal behavior," Indones. J. Chem., vol. 15, no. 3, pp. 281-287, 2015.

[20] H. M. N. El-din, M. F. Abou, and A. W. M. El-naggar, "Metal sorption and swelling characters of acrylic acid and sodium alginate based hydrogels synthesized by gamma irradiation," Beam Interact. with Mater. Atoms, vol. 266, no. 11, pp. 2607-2613, 2008.

[21] Y. Zhang, "Preparation of copolymers of acrylic acid and acrylamide for copper (II) capture from aqueous solutions," University of Waterloo, 2009.

[22] A. B. Morales-cepeda, "Hydrogels from poly (acrylic acid)/carboxymethyl cellulose \& poly (acrylic acid)/methyl celluloses," J. Mater. Online, vol. 4, pp. 1-9, 2008.

[23] A. M. Adel and A. M. Nada, "Carboxymethylated cellulose hydrogel; sorption behavior and characterization," Nat. Sci., vol. 8, no. 8, pp. 244-256, 2010.

[24] J. Ma, X. Li, and Y. Bao, "Advances in cellulose-based superabsorbent hydrogels," RSC Adv., vol. 5, no. 73, pp. 59745-59757, 2015.

[25] A. A. El-naggar, "Radiation synthesis of superabsorbent hydrogels based on carboxymethyl cellulose/sodium alginate for absorbent of heavy metal ions from waste water," $J$. Thermoplast. Compos. Mater., vol. 29, no. 1, pp. 1-12, 2014.

[26] T. M. Mututuvari and C. D. Tran, "Synergistic adsorption of heavy metal ions and organic pollutants by supramolecular polysaccharide composite materials from cellulose, chitosan and crown ether," J. Hazard. Mater., vol. 264, pp. 449-459, 2014.

[27] S. Yang, S. Fu, H. Liu, Y. Zhou, and X. Li, "Hydrogel beads based on carboxymethyl cellulose for removal heavy metal ions," J. Appl. Polym. Sci., vol. 119, pp. 1204-1210, 2010.

[28] N. Li and R. Bai, "Copper adsorption on chitosan-cellulose hydrogel beads: behaviors and mechanisms," Sep. Purif. Technol., vol. 42, pp. 237-247, 2005.

[29] S. Wang, T. Vincent, C. Faur, and E. Guibal, "Alginate and algal-based beads for the sorption of metal cations : $\mathrm{Cu}$ (II) and Pb (II)," Int. J. Mol. Sci., vol. 17, no. 1453, pp. 1-25, 2016.

[30] S. Hassan et al., "Investigation of copper $\left(\mathrm{Cu}^{2+}\right)$ adsorption performances and gamma radiation dose effect of polymeric hydrogel," AIP Adv., vol. 8, no. 025301, pp. 1-9, 2018.

[31] L. O. Ekebafe, D. E. Ogbeifun, and F. E. Okieimen, "Removal of heavy metals from aqueous media using native cassava starch hydrogel," African J. Environ. Sci. Technol., vol. 6, no. 7, pp. 275-282, 2012.

[32] M. Zhang et al., "Biomass based hydrogel as an adsorbent for the fast removal of heavy metal ions from aqueous solutions," J. Mater. Chem. A, vol. 5, no. 7, pp. 3434-3446, 2017. 